\title{
Long-term patterns of chironomid assemblages in a high elevation stream/lake network (Switzerland) - Implications to global change
}

\author{
Brigitte Lods-Crozet', Beat Oertli and Christopher T. Robinson ${ }^{3}$
}

Lods-Crozet B, Oertli B and Robinson CT. 2012. Long-term patterns of chironomid assemblages in a high elevation stream/lake network (Switzerland) - Implications to global change. Fauna norvegica 31: 71-85.

\begin{abstract}
A long-term monitoring program was initiated in 2002 on running and standing waters in a high elevation cirque landscape (Macun) in the Swiss National Park. The region comprises contrasting basins with different water sources, a glacier-fed basin and two precipitation-fed basins. Sampling of 26 permanent and temporary ponds (or small lakes) and of interconnecting streams (10 sites) was conducted from 2002 to 2010. Pond macroinvertebrate assemblages were dominated by chironomids with 42 taxa. The Orthocladiinae were the dominant subfamily in richness and abundance with 22 taxa. The greatest diversity was found in ponds located in the south and outlet basins. The inter-year variability for the same pond is high, but no clear temporal trend was noticed in ponds frequently monitored ponds. The Orthocladiinae subfamily was also the richest in the stream sites where 33 taxa were collected. The north and south basins were separated on the basis of chironomid assemblages. The chironomid assemblages in the stream network shows a temporal trend from 2002 but it cannot be linked to any clear change at the community structure level. The higher richness and abundance in stream sites and ponds of the south basin could be related to a greater heterogeneity in water physicochemistry and substrata, and by the presence of Bryophyta. The understanding of the environmental factors that influence faunal assemblages is crucial for the protection of this sensitive alpine pond network where a relatively high overall regional diversity (49 taxa) is detected. From the literature, temperature is recognized as the driving force on changes in chironomid assemblages in alpine systems. Our results support the use of chironomids as flagship indicators in the assessment of climatic change in alpine landscapes.
\end{abstract}

doi: 10.5324/fn.v31i0.1361. Received: 2011-10-04. Accepted: 2012-05-22.

Published on paper and online: 2012-10-17.

Keywords: Chironomidae, mountain, alpine biodiversity, temperature, pond

1. Musée of Zoology, Palais de Rumine, 1014 Lausanne, Switzerland

2. University of Applied Sciences Western Switzerland-hepia, 1254 Geneva, Switzerland

3. Department of Aquatic Ecology, EAWAG, 8600 Duebendorf, Switzerland

Corresponding author: Brigitte Lods-Crozet

E-mail: brigitte.lods@vd.ch

\section{INTRODUCTION}

High-elevation catchments in the Swiss Alps often include numerous small waterbodies interconnected by streams. Most alpine waterbodies originate during glacial recession, so-called cirque lakes, and many have inlet and outlet streams forming lake or pond chains along a large hydrographic system (Maiolini et al. 2006; Robinson \& Oertli 2009). Moreover, catchment characteristics can strongly influence their physico-chemistry (Robinson \& Matthaei 2007). Water sources can vary among surface waters, originating from glacier melt, groundwater, precipitation, and combinations of these (Tockner et al. 1997; Brown et al. 2003). Ephemeral and intermittent streams also are quite common in alpine environments (Robinson et al. 2003; Ruëgg \& Robinson 2004). Alpine lakes range in size and degree 
of connectedness; some being isolated waterbodies, while others are inter-connected by streams forming lake/pondchains. The juxtaposition of lakes and streams in alpine catchments enhances overall habitat heterogeneity and potentially enhances biodiversity. Relatively harsh environmental conditions such as very long winters under snow cover and low pond productivity and temperature further limit the composition and abundance of macroinvertebrates found in alpine freshwaters (LodsCrozet et al. 2001a; Ilg \& Castella 2006). Most studies of alpine streams and lakes document relatively low taxon richness and invertebrate abundances (Lods-Crozet et al. 2001a; Burgherr et al. 2002; Knispel \& Castella 2005; Hieber et al. 2005; Lencioni \& Rossaro 2005; Oertli et al. 2008; Hinden et al. 2005; Boggero \& Lencioni 2006; Maiolini et al. 2006; Robinson et al. 2007) .

This study is part of a long-term monitoring programme started in 2001 by the Swiss National Park, at the high altitude "Macun cirque". One of the preliminary steps towards monitoring was to establish the distribution patterns of macroinvertebrates with a specific focus on the taxonomic composition of assemblages. Previous investigations (Robinson et al. 2007; Oertli et al. 2008) revealed that chironomids were predominant with communities characteristized by stenothermic species in such high alpine ponds and streams. These considerations made them sensitive indicators of environmental change. It appears that the chironomid assemblages are a key group for monitoring.

The present study examined chironomid assemblages along two lake/pond chains interconnected by stream stretches in the same alpine catchment, each having a different water source (glacial and snowmelt/groundwater).

The objective of this paper was to summarize the distribution patterns of the chironomid fauna of permanent and temporary lakes/ponds and streams. A second objective was to analyse temporal changes over a 9 year period of study.

\section{Study area}

The Macun catchment $\left(46^{\circ} 44^{\prime} \mathrm{EN} 10^{\circ} 08^{\prime} \mathrm{E}\right)$ is a high alpine cirque ( $>2600 \mathrm{~m}$ a.s.l.) in the Canton Graubunden, Switzerland (Figure 1). The $3.6 \mathrm{~km}^{2}$ region was annexed to the Swiss National park in 2000 and currently is an area designed for long-term monitoring of alpine waterbodies (springs, streams, ponds, lakes).

The region comprises more than 35 small lakes or permanent ponds and around 10 small temporary ponds scattered within two sub-basins. A north basin is fed mostly by snowmelt and groundwater, whereas the south basin is fed by glacial melt from a number of rock glaciers. The surrounding peaks reach elevations between 2800 and $3000 \mathrm{~m}$, and the outlet stream (Zeznina) drains north to the river Inn in lower Engadine (Robinson \& Oertli 2008). Precipitation is low, typically being around $850 \mathrm{~mm}$ per year. Air temperature ranges from over $20^{\circ} \mathrm{C}$ in summer to below $-25^{\circ} \mathrm{C}$ in winter with a extended ice cover (9 months) (Robinson \& Kawecka 2005). Bedrock geology is crystalline (ortho-gneiss) rock. The area is above the tree line

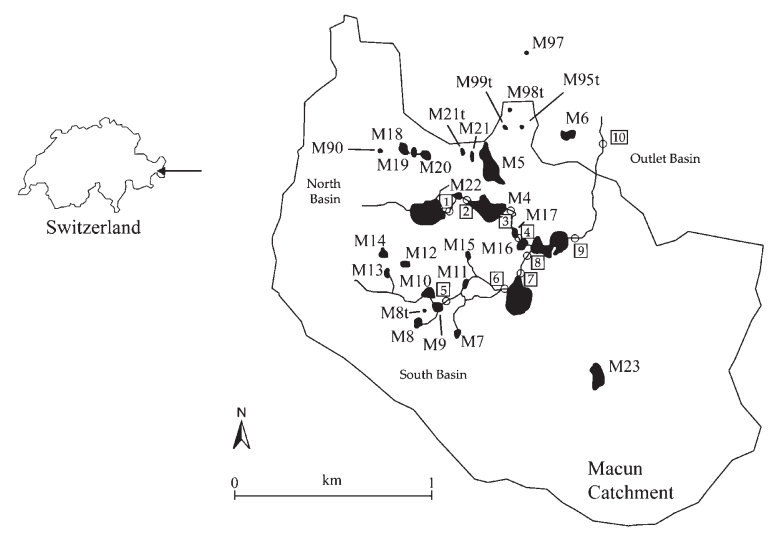

Figure I. Map of the Macun Lakes region showing the location of stream sites ( $\mathrm{n}^{\circ} 1$ to 10 ; open squares) and lakes/ponds (M4 to M99); t: temporary pond.

and the drainage area of each pond is characterised by a mixture of two types of land cover, rock and alpine grassland.

Of the 35 standing waterbodies, a subset of 26 ponds was selected for sampling (Figure 1), including 21 permanent and 5 temporary ponds. The choice included all types of ponds: different sizes (area and depth) and magnitude of water level fluctuations, permanence or temporarity, location in the north or south basin, and connected or not to streams. A description of pond morphometry and selected physico-chemical parameters is presented in Table 1. Low $\mathrm{pH}$ (mean: $6.3-6.8$ ) and low conductivity (mean: $10.4-16.3 \mu \mathrm{S} / \mathrm{cm}$ ), except in pond M6 (84 $\mu \mathrm{S} / \mathrm{cm}$ ) characterized these waterbodies. Aquatic vegetation is present in 9 ponds. Bryophyta ( 7 taxa) are the main aquatic plants. Helophytes colonised the lower elevation pond (M6) with four taxa (Eleocharis sp., Eriophorum scheuzeri, Glyceria sp., Saxifraga stellaris). Five of the sampled ponds (M4, M5, M14, M16, M17) had fish (Salmo trutta fario, Salvenius namaycush, Phoxinus phoxinus), and were last stocked in 1993 (Oertli et al. 2008).

Ten sites were sampled for streams: four in the north basin (sites 1 - 4), three in the south basin $(5-8)$ and two in the outlet stream $(9-10)$ (Figure 1). The sites were situated at the inlets and outlets of the prominent lakes in each basin along a longitudinal gradient.

The different origin in each basin affects the physicochemical characteristics of the running waters (Robinson \& Matthaei, 2007). The south basin had temperatures on average $4^{\circ} \mathrm{C}$ cooler and temperature generally increased for all sites for years grouped as 2001-2004 and those grouped as 2006-2010 (Robinson \& Oertli 2009). Total dissolved nitrogen levels in the south basin were twice the amounts found in the north basin (Table 2). Conductivity was low but increasing along the longitudinal gradient (mean: $6.6-15.1 \mu \mathrm{S} / \mathrm{cm}$ ). The $\mathrm{pH}$ of the stream was acid or near neutral $(6.0-7.5)$. The turbidity was low in the stream network and higher in the outlet stream (site 10) due to a strong influence of a rock glacier. 
Table I. Description of environmental parameters characterising permanent and temporary ponds sampled between 2002 and 2009.

\begin{tabular}{lcccccccc}
\hline & \multicolumn{3}{c}{ 21 permanent ponds $($ ponds $\mathrm{x}$ dates $=29)$} & \multicolumn{3}{c}{5 temporary ponds (ponds $\mathrm{x}$ dates $=10)$} \\
& mean & $\mathrm{SD}$ & $\min$ & $\max$ & $\operatorname{mean}$ & $\mathrm{SD}$ & $\min$ & $\max$ \\
\hline Altitude $(\mathrm{m}$ a.s.l.) & 2651.8 & 38.2 & 2551.0 & 2714.0 & 2633.8 & 32.7 & 2600.0 & 2669.0 \\
Pond area $\left(\mathrm{m}^{2}\right)$ & 2099.9 & 2855.0 & 98 & 12750 & 40.6 & 31.3 & 18 & 122 \\
Mean depth $(\mathrm{m})$ & 1.2 & 1.0 & 0.3 & 4.5 & 0.1 & 0.0 & 0.05 & 0.15 \\
Max depth $(\mathrm{m})$ & 2.5 & 2.2 & 0.7 & 10 & 0.2 & 0.1 & 0.1 & 0.35 \\
$\mathrm{pH}^{\mathrm{a}}$ & 6.3 & 0.5 & 5.3 & 7.5 & 6.8 & 1.2 & 5.5 & 8.52 \\
Conductivity $(\mathrm{\mu S} / \mathrm{cm})$ & 10.4 & 18.6 & 1.7 & 84 & 16.3 & 10.2 & 5.3 & 35.3 \\
Total nitrogen $(\mathrm{mg} / \mathrm{L})^{\mathrm{a}}$ & 0.25 & 0.10 & 0.05 & 0.50 & 0.3 & 0.1 & 0.13 & 0.36 \\
Alpine grassland in drainage area $(\%)$ & 48 & 27 & 10 & 100 & 40.0 & 30.8 & 10 & 80 \\
\hline
\end{tabular}

${ }^{a}$ Measured on a subset of 18 ponds $\mathrm{x}$ date

Table 2. Description of environmental parameters characterising stream sites sampled between 2002 and 2010.

\begin{tabular}{lcccccccccccc}
\hline & \multicolumn{4}{c}{ North basin } & \multicolumn{4}{c}{ South basin } & \multicolumn{4}{c}{ Outlet stream } \\
& mean & SD & $\min$ & $\max$ & $\operatorname{mean}$ & $\mathrm{SD}$ & $\min$ & $\max$ & $\operatorname{mean}$ & $\mathrm{SD}$ & $\min$ & $\max$ \\
\hline Temperature $\left({ }^{\circ} \mathrm{C}\right)$ & 12.4 & 3.5 & 3.9 & 19.5 & 8.9 & 3.2 & 2.1 & 14.2 & 9.0 & 3.1 & 2.8 & 15.4 \\
$\mathrm{pH}$ & 6.8 & 0.4 & 6.1 & 7.8 & 6.7 & 0.5 & 6.0 & 7.6 & 6.9 & 0.3 & 6.4 & 7.3 \\
Conductivity $\left(\mu \mathrm{S} / \mathrm{cm} 20^{\circ} \mathrm{C}\right)$ & 6.6 & 0.8 & 5.3 & 9.0 & 10.2 & 3.9 & 5.3 & 24.0 & 15.1 & 13.5 & 2.6 & 79.0 \\
Turbidity $(\mathrm{NTU})$ & 1.9 & 2.4 & 0.2 & 18.2 & 1.8 & 2.0 & 0.1 & 9.1 & 6.0 & 7.5 & 0.3 & 27.9 \\
Total dissolved nitrogen & 0.14 & 0.09 & 0.05 & 0.61 & 0.25 & 0.13 & 0.05 & 0.52 & 0.21 & 0.12 & 0.05 & 0.47 \\
$(\mathrm{mg} / \mathrm{L})$ & & & & & & & & & & & & \\
\hline
\end{tabular}

\section{METHODS}

\section{Chironomid sampling}

The biomonitoring of the small stagnant waterbodies were initiated in summer 2002 (16-22 July), followed by collections in 2004 (27 July- 2 August), 2005 (17-26 July), 2007 (27-28 July) and 2009 (2-5 August). The standardised procedure "PLOCH" (Oertli et al. 2005) was used for sampling macroinvertebrates. They were collected by a small-framed hand-net (rectangular frame $14 \times 10 \mathrm{~cm}$, mesh size $0.5 \mathrm{~mm}$ ). For each sample, the net was swept through the water intensively for 30 to 60 seconds. The number of samples taken ranged from 2 to 20, depending on pond size. Sampling was stratified for the dominant habitats (from the land-water interface to a depth of $2 \mathrm{~m}$ ): stones, gravel, sand and bryophytes.

For streams, the biomonitoring was done in summer 2002 (16-22 July), 2004 (27 July- 2 August), 2006 (17-27 July), 2007 (27-28 July) and 2010 (29-30 July). Chironomid larvae and pupae were sampled semi-quantitatively using a timed $(5 \mathrm{~min})$ kick-net approach (250 $\mathrm{mm}$ mesh). Along a $30-\mathrm{m}$ reach, benthic substrata were disturbed and the loosened material collected in the net $(250 \mathrm{~mm}$ mesh). Primary habitat types (e.g., pools, runs, riffles) were sampled proportionally during the $5 \mathrm{~min}$ sample. In all cases, the collected material was preserved in $70 \%$ ethanol and then sorted in the laboratory. Chironomid specimens (larvae and pupae) were identified to species /genus (Wiederholm 1983, 1986; Langton 1991; Schmid 1993; Saether 1995; Brooks et al. 2007; Lencioni et al. 2007; Ilyashuk et al. 2010). Collection material was deposited in the Museum of Zoology in Lausanne (Switzerland).

\section{Data analysis}

Physico-chemical data were summarized as means and standard deviations for the different study sites. Chironomids were summarized first using species group as one taxon for estimates of taxon richness, abundances per sample and occurrence (as $\%$ ). Mean richness and abundance were compared between north and south basin stream sites using a non-parametric Mann-Whitney U-test.

Given the heterogeneity of abundances between samples, the taxonomic richness was calculated using the rarefaction procedure (Heck et al. 1975; Krebs 1999). Rarefaction simulates random draws of a fixed number of individuals within the samples (or combined samples) to be compared. The number of individuals drawn is based upon the least abundant sample. Rarefied richness is not an estimate of the total community richness, but it allows an unbiased comparison between samples of unequal abundances. It can also be regarded as a diversity measure, because, for a given number of observed taxa in a sample, rarefied richness will increase with the evenness of 


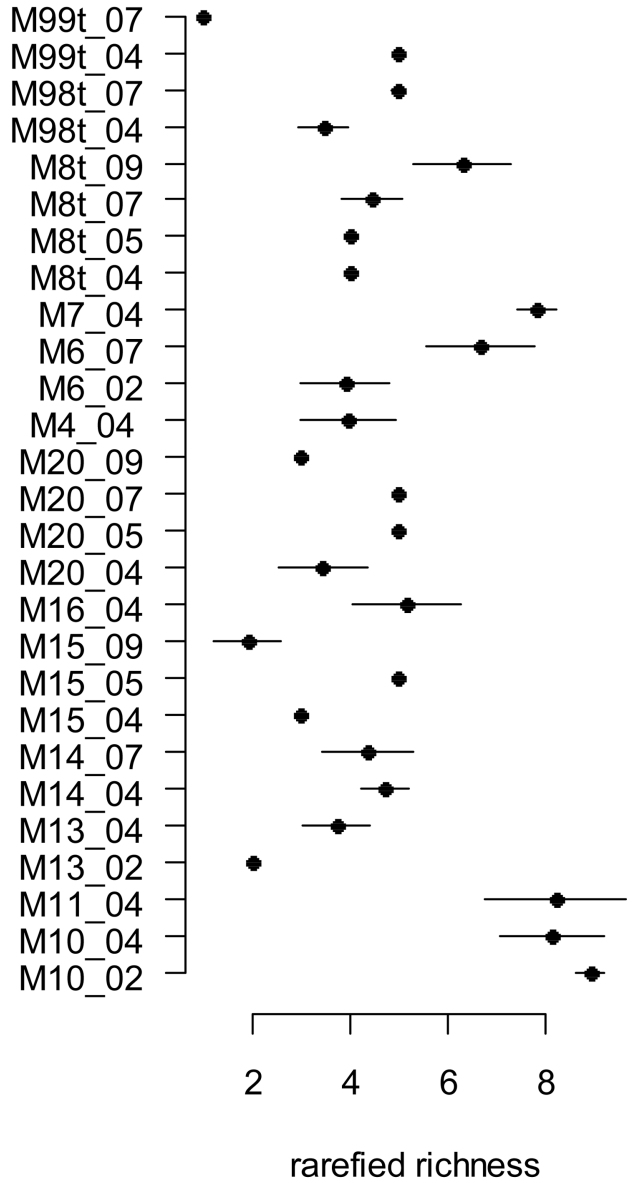

Figure 2. Rarefied richness (average number of chironomid taxa for 50 individuals $\pm 1 \mathrm{SE})$, calculated for 27 ponds $\mathrm{x}$ dates. the distribution of abundance between taxa. Calculations were performed with the function "rarefy" from the "vegan" library in the R software (R Development Core Team 2009). The function calculates the rarefied richness for a given number of individuals from the Hurlbert (1971) formula, together with a standard error following Heck et al. (1975). Stream data from regrouped taxa (Diamesa gr. latitarsis, D. gr. zernyi/cinerella, Corynoneura spp., Eukiefferiella spp.) and representing at least $5 \%$ of occurrence were then examined using Correspondence analysis (CA) on log-transformed values and associated with between-class Correspondence Analyses (Dolédec \& Chessel 1987, 1989). A Monte-Carlo permutation test (999 replicates) was then performed. All multivariate analyses were carried out using the ade4 library (Chessel et al. 2004) for the R software (R development core team 2009).

\section{RESULTS}

\section{Chironomid assemblages in Macun permanent and temporary ponds}

In the 26 ponds sampled between 2002 and 2009, 42 taxa were collected, 24 of which were identified to the species level. The Orthocladiinae were the dominant subfamily with 22 taxa followed by Diamesinae, tribe Tanytarsini ( 9 and 8 taxa each) and Tanypodinae (3 taxa) (Table 3).

In 21 permanent ponds sampled one to four times through the sampling period, 37 taxa were found. Zavrelimyia melanura (Meigen) (63\%) was the most frequent species followed by Paratanytarsus austriacus (Kieffer) (50\%), Heterotrissocladius marcidus (Walker) (47\%), Corynoneura scutellata gr. (43\%), Pseudodiamesa nivosa (Goetghebuer) and Limnophyes sp.



Figure 3. Ordination by Correspondence Analysis (CA) of the 10 stream sites-years according to their chironomid composition (20 taxa); left: ordination of the samples grouped by basin; right: ordination of the taxa (see abbreviations in Table 4). 


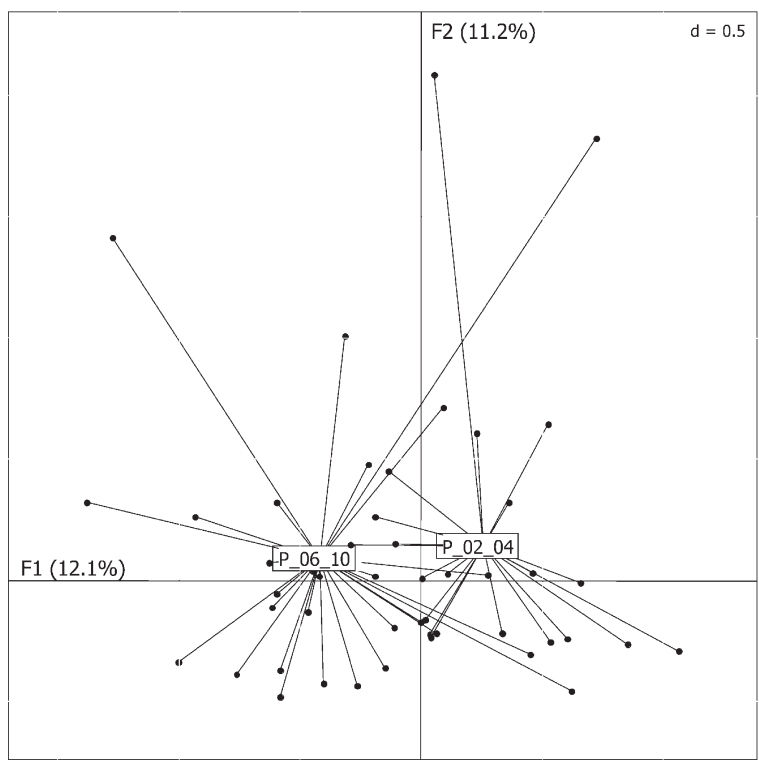

Figure 4. Ordination by Between-Class Correspondence Analysis (CA) of the 10 stream site-years according to two years-periods (2002-04; 2006-10).

( $40 \%$ both). The same two most frequent were also the most abundant taxa in the samples. The global taxonomic richness was the highest in ponds M6, M10 and M11 (15 taxa), followed by M4 and M16 (11 and 10, respectively), independent of sampling effort.

Zavrelimyia melanura and Heterotrissocladius genus are mainly associated with the largest and deepest lakes in the catchment. Lake M23 located in the southeastern part of the Macun cirque, sampled in 2002 and strongly influenced by glacial-melt waters, was only colonised by Diamesa steinboecki (Goetghebuer) and Pseudodiamesa nivosa. Pond M6, lower in altitude and colonized by a rich community of aquatic vegetation, had chironomid assemblages characterized by a high abundance of Cricotopus sylvestris gr., Psectrocladius sordidellus (Zetterstedt), Tanytarsus sinuatus Goetghebuer and Paratanytarsus austriacus. The first three species are rare or absent in the other ponds. This pond was also the only one with a higher conductivity $(76.1 \pm 11.1)$ and a different ionic composition.

The Diamesinae (Diamesa steinboecki, D. latitarsis gr., D. bertrami Edwards, Pseudokiefferiella parva (Edwards)) and Limnophyes sp. were more frequently collected in the ponds of the southern basin influenced by glacial runoff (Table 3). Corynoneura scutellata gr. contributed more to pond biodiversity in the north basin influenced by snowmelt and groundwater than in the south basin.

In the 5 temporary ponds sampled one to five times through the sampling period, 22 taxa were found. Diamesa zernyi gr., Parametriocnemus stylatus Kieffer were the most frequent (45\%) with Pseudokiefferiella parva, Limnophyes sp. and Metriocnemus ursinus (Holmgren) (36\%). Diamesa zernyi gr. and Pseudodiamesa sp. contributing the most to abundance. The temporary pond M8t, monitored at 5 occasions, had the highest cumulative richness (15 taxa).

Diversity estimated by rarefied richness (Figure 2), was also the highest in ponds M10 and M11, followed by M7, M6 in 2007 and M8t in 2009. All these ponds are located in the south basin, excepted for M6 (outlet basin). Further, the inter-year variability for the same pond/lake is high, but no clear temporal trend was noticed in frequently monitored ponds, such as M15, M20 and M8t.

Among a total of 42 taxa, 17 were common to permanent and temporary ponds. Diamesinae and Orthocladiinae were the major contributors $(91 \%)$ for temporary ponds, whereas Tanypodinae and Tanytarsini acted as significant groups (30\%) in permanent ponds.

\section{Chironomid assemblages in the stream network}

A total of 33 taxa were collected from the 10 sites, 22 of which were identified to species. The Orthocladiinae were the dominant subfamily as in the pond system with 21 taxa followed by Diamesinae ( 9 taxa), Tanytarsini ( 2 taxa) and Tanypodinae (1 taxa) (Table 4).

Diamesa zernyi/cinerella gr., Pseudodiamesa branickii (Nowicki), Pseudokiefferiella parva, Tokunagaia rectangularis (Goetghebuer) and Tvetenia calvescens (Edwards) were the predominant taxa in frequency and abundance. Parametriocnemus stylatus was frequently found $(50 \%$ of the samples) but not abundant. The mean richness per stream site was $6.4 \pm 0.4$ taxa (Table 5). Mean taxa richness was significantly different between basins (north $=4.7$, south $=$ 7.7). Mean chironomid abundance (individuals $/ 5$ min sample) was 165.8 and ranged from 14.8 at site 1 to 371.2 at site 6 . The south basin supported a greater chironomid abundance (290 ind/sample), significantly different than the north basin (51 ind/sample) (Table 5).

Mean taxon richness was not significantly different between inlets $(6.1 \pm 0.7)$ and outlets $(6.5 \pm 0.6)$ and similar abundances were found between inlets (197 $\pm 79.8 \mathrm{ind} / \mathrm{sample})$ and outlets $(161 \pm 29.1 \mathrm{ind} / \mathrm{sample})$.

The CoA results on 20 taxa at 50 sites $\mathrm{x}$ dates distinguished 3 major groups of sites: north basin sites, south basin sites, and Zeznina basin sites 9 and 10 (permutation test, $p=0.002$ ). The first two axes of the CoA explained $23.3 \%$ of the variation among sites. The two basins were separated from the outlet stream (site 10) along axis-1 according to the chironomid assemblages (Corynoneura spp. and Micropsectra spp.) (Figure 3). Site 9 was placed intermediate along axis-2. Axis- 2 separated the two basins: north basin with Diamesa zernyi/cinerella, Pseudodiamesa branickii, Rheocricotopus effusus (Walker) and south basin with Diamesa gr. latitarsis, Pseudokiefferiella parva, Tokunagaia rectangularis, Tvetenia calvescens.

The between class CoA showed a clear separation in the chironomid assemblages (permutation test, $p=0.001$ ) between periods 2002-04 and 2006-07-10 (identified by the water 
Table 3. List of Chironomidae species identified, occurrence (\%) and abundance (no per site-year) in 21 permanent and 5 temporary ponds between 2002 and 2009; S: south basin; N: north basin; O: outlet basin, n: number of samples.

\begin{tabular}{rrrrrrrrrrrrrccccc}
\hline Pond & M7 & M8 & M9 & M10 & M10 & M11 & M12 & M13 & M13 & M14 & M14 & M15 & M15 & M15 \\
Year & 2004 & 2004 & 2004 & 2002 & 2004 & 2004 & 2004 & 2002 & 2004 & 2004 & 2007 & 2004 & 2005 & 2009 \\
Basin & S & S & S & S & S & S & S & S & S & S & S & S & S & S \\
n & 2 & 2 & 2 & 3 & 4 & 2 & 1 & 2 & 2 & 2 & 8 & 1 & 1 & 7 \\
\hline
\end{tabular}

Macropelopia sp.

Procladius choreus (Meigen)

Zavrelimyia melanura (Meigen)

Diamesa steinboecki (Goetghebuer)

Diamesa bertrami Edwards

Diamesa latitarsis gr.

Diamesa zernyi gr.

Diamesa spp. (juv.)

Pseudodiamesa sp.

Pseudodiamesa branickii (Nowicki)

Pseudodiamesa nivosa (Goetghebuer)

Pseudokiefferiella parva (Edwards)

Bryophaenocladius sp.

Chaetocladius sp. ${ }^{\text {a }}$

Corynoneura scutellata gr.

Cricotopus (Isocladius) sp.

Cricotopus / Orthocladius sp.

Eukiefferiella / Tokunagaia sp.

Heterotrissocladius grimshawi (Edwards)

Heterotrissocladius marcidus (Walker)

Limnophyes sp.

Metriocnemus eurynotus (Holmgren)

Metriocnemus ursinus (Holmgren)

Metriocnemus sp.

Orthocladius (Euorthocladius) sp.

Orthocladius (Orthocladius) sp.

Parametriocnemus stylatus Kieffer

Paraphaenocladius $\mathrm{sp}^{\mathrm{b}}$

Parorthocladius nudipennis (Kieffer in Kieff.

\& Thien.)

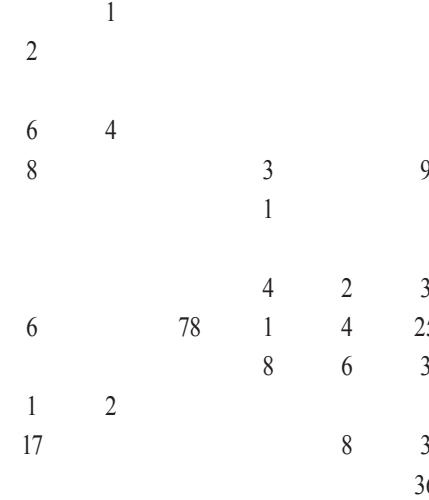

(27)

$83 \quad 6$

Psectrocladius sordidellus (Zetterstedt)

Pseudosmittia arenaria Strenzke

Pseudosmittia oxoniana (Edwards)

Rheocricotopus effusus (Walker)

Tokunagaia rectangularis (Goetghebuer)

Micropsectra junci (Meigen)

Micropsectra notescens (Walker)

Micropsectra radialis Goetghebuer

Micropsectra sp.

Paratanytarsus austriacus (Kieffer)

Tanytarsus sp.

Tanytarsus bathophilus Kieffer

Tanytarsus sinuatus Goetghebuer

\begin{tabular}{lllllllllllllll}
\hline $\mathrm{Nb}$ taxa & 9 & 5 & 1 & 10 & 10 & 15 & 2 & 2 & 6 & 5 & 7 & 3 & 4 & 5 \\
\hline
\end{tabular}

a : among which C. melaleucus (Meigen)

$\mathrm{b}$ : among which $P$. cf. pseudoirritus Strenzke 


\begin{tabular}{|c|c|c|c|c|c|c|c|c|c|c|c|c|c|c|c|c|c|}
\hline M23 & M4 & M5 & M16 & M17 & M18 & M19 & M20 & M20 & M20 & M20 & M21 & M22 & M90 & M6 & M6 & Occurrence & Abundance \\
\hline 2002 & 2004 & 2002 & 2004 & 2004 & 2004 & 2004 & 2004 & 2005 & 2007 & 2009 & 2004 & 2002 & 2007 & 2002 & 2007 & $\%$ & \\
\hline S & $\mathrm{N}$ & $\mathrm{N}$ & $\mathrm{N}$ & $\mathrm{N}$ & $\mathrm{N}$ & $\mathrm{N}$ & $\mathrm{N}$ & $\mathrm{N}$ & $\mathrm{N}$ & $\mathrm{N}$ & $\mathrm{N}$ & $\mathrm{N}$ & $\mathrm{N}$ & $\mathrm{O}$ & 0 & & \\
\hline 2 & 2 & 7 & 2 & 2 & 1 & 2 & 2 & 7 & 6 & 3 & 2 & 1 & 2 & 5 & 13 & & \\
\hline \multirow{10}{*}{3} & & & & & & & & & & & & & & & 3 & 3.3 & 3 \\
\hline & 6 & & & & & & & & & & & & & & & 3.3 & 6 \\
\hline & 1027 & 60 & 467 & 38 & 145 & & 97 & 3 & 5 & & 1 & & 4 & 3 & & 63.3 & 2355 \\
\hline & & & & & & & & & & & & & & & & 6.7 & 5 \\
\hline & & & & & & & & & & & & & & & & 0.0 & 0 \\
\hline & & & & & & & & & & & & & & & & 6.7 & 10 \\
\hline & 43 & & 4 & & & & & 1 & & & & & & & & 20.0 & 68 \\
\hline & & & & & & & & & & & & & & & & 3.3 & 1 \\
\hline & & & & & & & & & 9 & & & & & & 22 & 10.0 & 80 \\
\hline & & & & & & & & & & & & & & 1 & 3 & 16.7 & 9 \\
\hline \multirow[t]{32}{*}{4} & & & 65 & & 8 & & & & & & & & 36 & & 18 & 40.0 & 234 \\
\hline & & & & & & & & & & 3 & & & & & 72 & 16.7 & 20 \\
\hline & & & 7 & 1 & & & & & & & 11 & & & & & 26.7 & 33 \\
\hline & 1 & & & & & & & & & & & & & 1 & & 16.7 & 29 \\
\hline & 20 & 22 & 2 & 7 & 2 & & 2 & 1 & & 2 & & & 1 & & 2 & 43.3 & 1374 \\
\hline & & & & & & & & & & & & & & 64 & 9 & 10.0 & 26 \\
\hline & 1 & & & & & & 1 & & & & & & & & 1 & 16.7 & 13 \\
\hline & & & & & 1 & & & & & & & & & & & 13.3 & 309 \\
\hline & 5 & & & & & & & & & & & & & & & 3.3 & 5 \\
\hline & 46 & 1 & 117 & 105 & 7 & & 2 & & 1 & & & & 8 & & 42 & 46.7 & 338 \\
\hline & & & 8 & 5 & & & & & & & & & & 1 & & 40.0 & 82 \\
\hline & & & 2 & & & & & & & & & & & & & 10.0 & 4 \\
\hline & & & & & & & & & & & & & & & & 6.7 & 41 \\
\hline & & & & & & & & & & & & & & & & 0.0 & 0 \\
\hline & & & & & & & & & & & & & & & & 0.0 & 0 \\
\hline & & & & & & & & & & & & & & & & 0.0 & 0 \\
\hline & & & & & & & & & & & & & & & & 10.0 & 25 \\
\hline & & & & & & & & & & & & & & & & 0.0 & 0 \\
\hline & & & & & & & & & & & & & & & & 3.3 & 7 \\
\hline & & & & & & & & & & & & & & 8 & 89 & 6.7 & 0 \\
\hline & & & & & & 1 & & & & & & & & & & 10.0 & 3 \\
\hline & & & & & & & & & & & & & & & & 3.3 & 2 \\
\hline & 2 & & 2 & & & 3 & & & & & & & & & & 13.3 & 25 \\
\hline & & & & & & & & & & & & & & & & 6.7 & 8 \\
\hline & & & & & & 1 & & & & & & & & & & 3.3 & 1 \\
\hline & & & & & & 1 & & & & & & & & & & 6.7 & 5 \\
\hline & & & & & & & & & & & & & 3 & & & 6.7 & 4 \\
\hline & & & & & & 2 & & & & & & & & & & 10.0 & 9 \\
\hline & 4 & 2 & 13 & & & & 1 & 2 & 3 & 1 & & 4 & & 177 & 790 & 50.0 & 42 \\
\hline & 1 & & & & & & & & 1 & & & & & & & 6.7 & 2 \\
\hline & & & & & & & & 1 & & & & & & & & 6.7 & 7 \\
\hline & & & & & & & & & & & & & & & 48 & 3.3 & 0 \\
\hline 2 & 11 & 4 & 10 & 5 & 5 & 5 & 5 & 5 & 5 & 3 & 2 & 1 & 5 & 7 & 12 & & \\
\hline
\end{tabular}

Continued on next page. 
Table 3. Continued.

\begin{tabular}{|c|c|c|c|c|c|c|c|c|c|c|c|c|c|}
\hline Pond & M8t & M8t & M8t & M8t & M8t & M21t & M95t & M98t & M98t & M99t & M99t & Occurrence & Abundance \\
\hline Year & 2002 & 2004 & 2005 & 2007 & 2009 & 2007 & 2007 & 2004 & 2007 & 2004 & 2007 & $\%$ & \\
\hline Basin & S & $\mathrm{S}$ & S & S & S & $\mathrm{N}$ & $\mathrm{N}$ & $\mathrm{N}$ & $\mathrm{N}$ & $\mathrm{N}$ & $\mathrm{N}$ & & \\
\hline $\mathrm{n}$ & 1 & 2 & 3 & 2 & 5 & 1 & 1 & 2 & 1 & 1 & 1 & & \\
\hline Macropelopia sp. & & & & & & & & & & & & 0.0 & 0 \\
\hline Procladius choreus (Meigen) & & & & & & & & & & & & 0.0 & 0 \\
\hline Zavrelimyia melanura (Meigen) & & 4 & & & & & & & & & & 9.1 & 4 \\
\hline Diamesa steinboecki (Goetghebuer) & 1 & & & & & & & & & & & 9.1 & 1 \\
\hline Diamesa bertrami Edwards & & & & & 1 & & & & & & & 9.1 & 1 \\
\hline Diamesa latitarsis gr. & & & & & 1 & & & & & & & 9.1 & 1 \\
\hline Diamesa zernyi gr. & & & 22 & 71 & 163 & & & 79 & 15 & & & 45.5 & 350 \\
\hline Diamesa spp. (juv.) & & & & & & & & & & & & 0.0 & 0 \\
\hline Pseudodiamesa sp. & & & & 135 & & & & & & & & 9.1 & 135 \\
\hline Pseudodiamesa branickii (Nowicki) & & & & & 16 & & & & 80 & & & 18.2 & 96 \\
\hline Pseudodiamesa nivosa (Goetghebuer) & & & 25 & & 8 & & & & & 1 & & 27.3 & 34 \\
\hline Pseudokiefferiella parva (Edwards) & & 4 & 9 & 4 & 13 & & & & & & & 36.4 & 30 \\
\hline Bryophaenocladius sp. & & & & & & 1 & & 1 & & 2 & & 27.3 & 4 \\
\hline Chaetocladius sp. ${ }^{\text {a }}$ & & & & & & & & & 12 & & & 9.1 & 12 \\
\hline Corynoneura scutellata gr. & & & & & & & & & & & & 0.0 & 0 \\
\hline Cricotopus (Isocladius) sp. & & & & & & & & & & & & 0.0 & 0 \\
\hline Cricotopus / Orthocladius sp. & & & & & & & & & & & & 0.0 & 0 \\
\hline Eukiefferiella / Tokunagaia sp. & & & & & & & & & & & & 0.0 & 0 \\
\hline Heterotrissocladius grimshawi (Edwards) & & & & & & & & & & & & 0.0 & 0 \\
\hline Heterotrissocladius marcidus (Walker) & & & & & & & & & & 2 & & 9.1 & 2 \\
\hline Limnophyes sp. & & 3 & & 8 & & & & 19 & & 2 & & 36.4 & 32 \\
\hline Metriocnemus eurynotus (Holmgren) & & & & & 4 & & & & & & & 9.1 & 4 \\
\hline Metriocnemus ursinus (Holmgren) & & 4 & & & 3 & & 1 & & & & 1 & 36.4 & 9 \\
\hline Metriocnemus sp. & & & & & & & 5 & & & & 50 & 18.2 & 55 \\
\hline Orthocladius (Euorthocladius) sp. & & & & & 1 & & & & & & & 9.1 & 1 \\
\hline Orthocladius (Orthocladius) sp. & & & & & & & & & 9 & & & 9.1 & 9 \\
\hline Parametriocnemus stylatus Kieffer & & & 8 & 14 & 5 & & 3 & 6 & & & & 45.5 & 36 \\
\hline Paraphaenocladius sp. ${ }^{\mathrm{b}}$ & & & & & & & 20 & & & 1 & & 18.2 & 21 \\
\hline $\begin{array}{l}\text { Parorthocladius nudipennis (Kieffer in } \\
\text { Kieff. \& Thien.) }\end{array}$ & & & & & & & & & & & & 0.0 & 0 \\
\hline Psectrocladius sordidellus (Zetterstedt) & & & & & & & & & & & & 0.0 & 0 \\
\hline Pseudosmittia arenaria Strenzke & & & & & & & & & & & & 0.0 & 0 \\
\hline Pseudosmittia oxoniana (Edwards) & & & & & & & & & & & & 0.0 & 0 \\
\hline Rheocricotopus effusus (Walker) & & & & & 1 & & & & & & & 9.1 & 1 \\
\hline Tokunagaia rectangularis (Goetghebuer) & & & & & & & & & & & & 0.0 & 0 \\
\hline Micropsectra junci (Meigen) & & & & & & & & & & & & 0.0 & 0 \\
\hline Micropsectra notescens (Walker) & & & & & & & & & & & & 0.0 & 0 \\
\hline Micropsectra radialis Goetghebuer & & & & & & & & & & & & 0.0 & 0 \\
\hline Micropsectra sp. & & & & & & & & & & & & 0.0 & 0 \\
\hline Paratanytarsus austriacus (Kieffer) & & & & & & & & & & & & 0.0 & 0 \\
\hline Tanytarsus sp. & & & & & & & & & 9 & & & 9.1 & 9 \\
\hline Tanytarsus bathophilus Kieffer & & & & & & & & & & & & 0.0 & 0 \\
\hline Tanytarsus sinuatus Goetghebuer & & & & & & & & & & & & 0.0 & 0 \\
\hline
\end{tabular}

\begin{tabular}{llllllllllll}
\hline $\mathrm{Nb}$ taxa & 1 & 4 & 4 & 5 & 11 & 1 & 4 & 4 & 5 & 5 & 2
\end{tabular}

a : among which C. melaleucus (Meigen)

$\mathrm{b}$ : among which $P$. cf. pseudoirritus Strenzke 


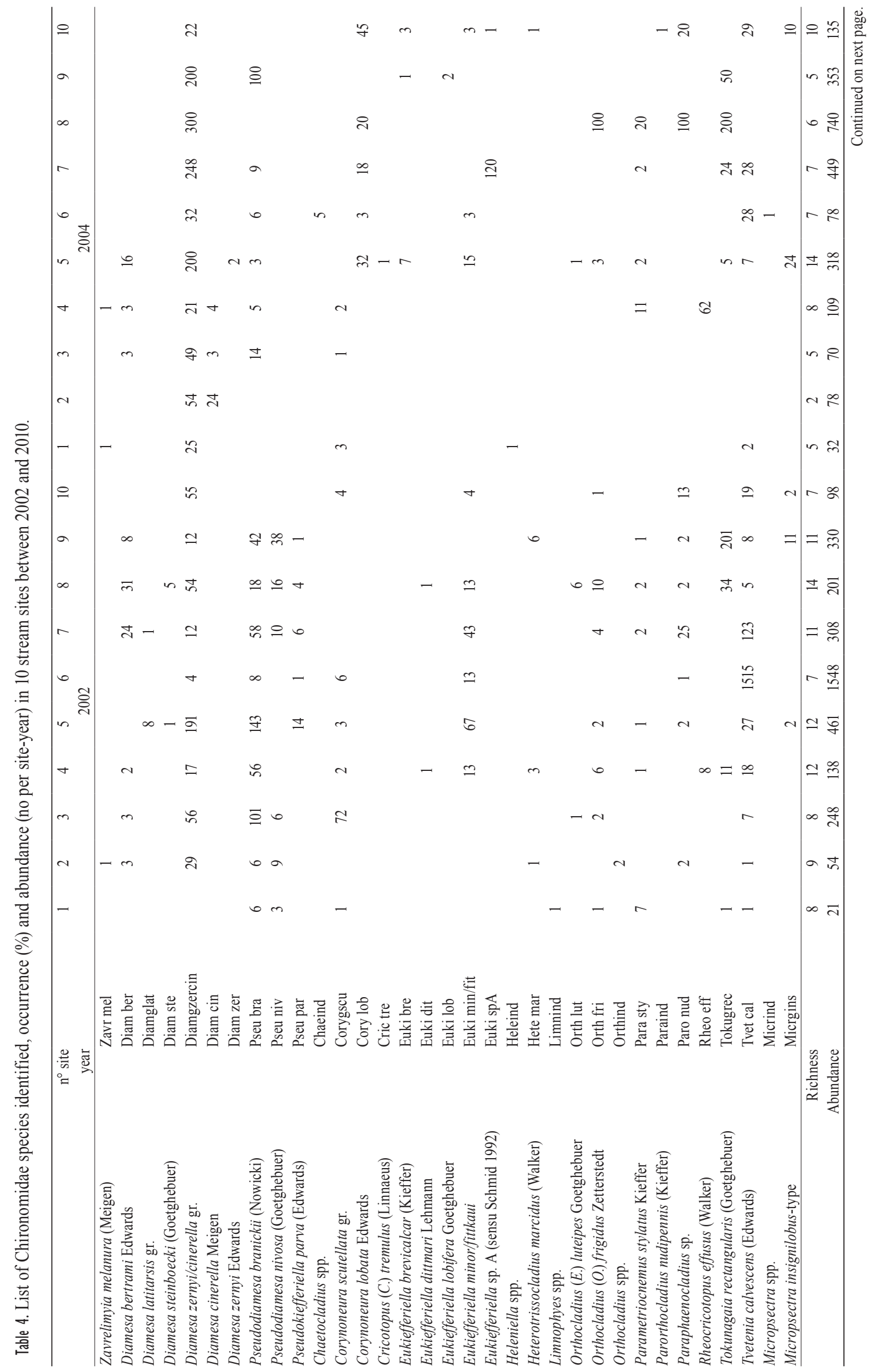




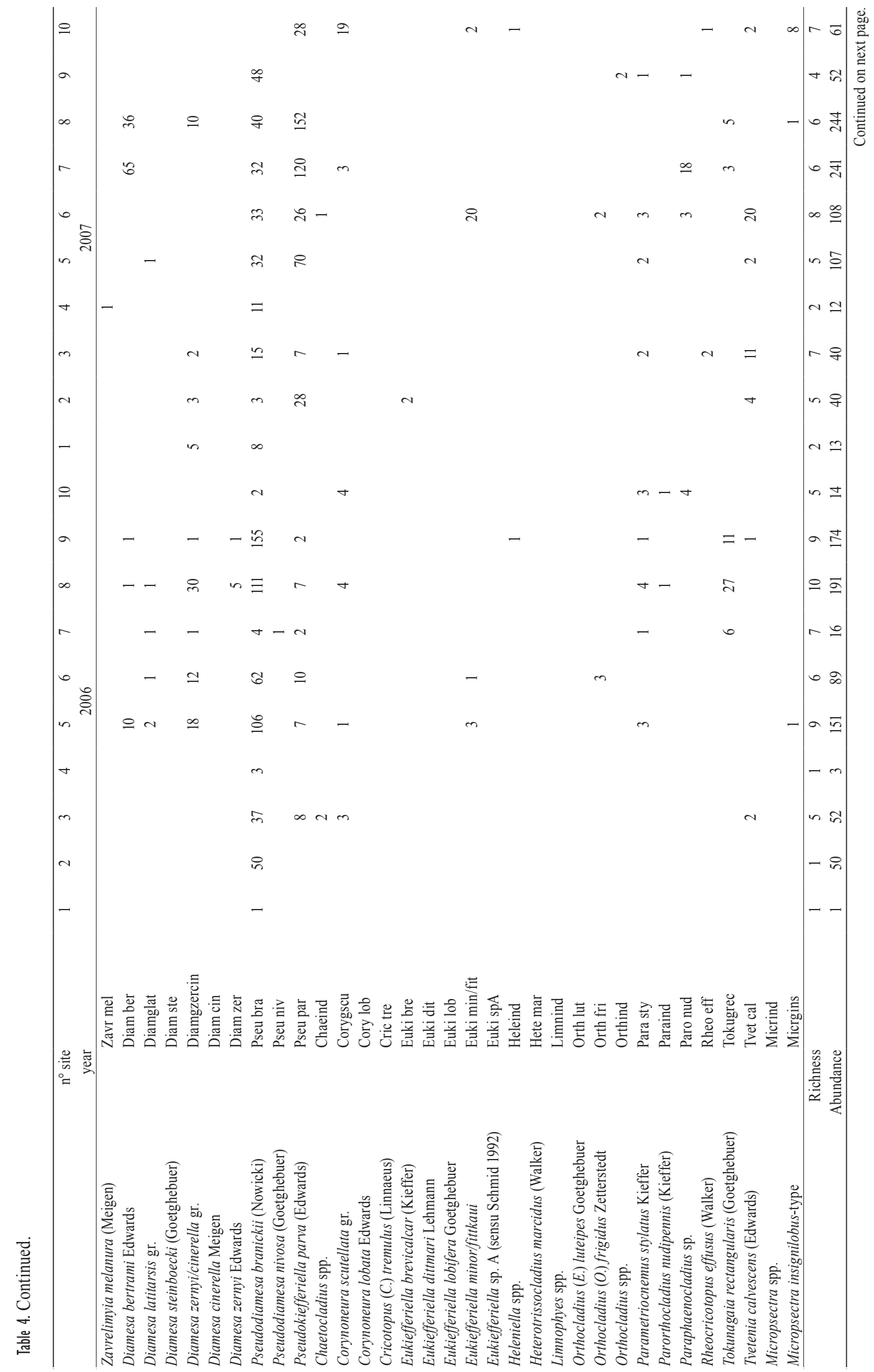




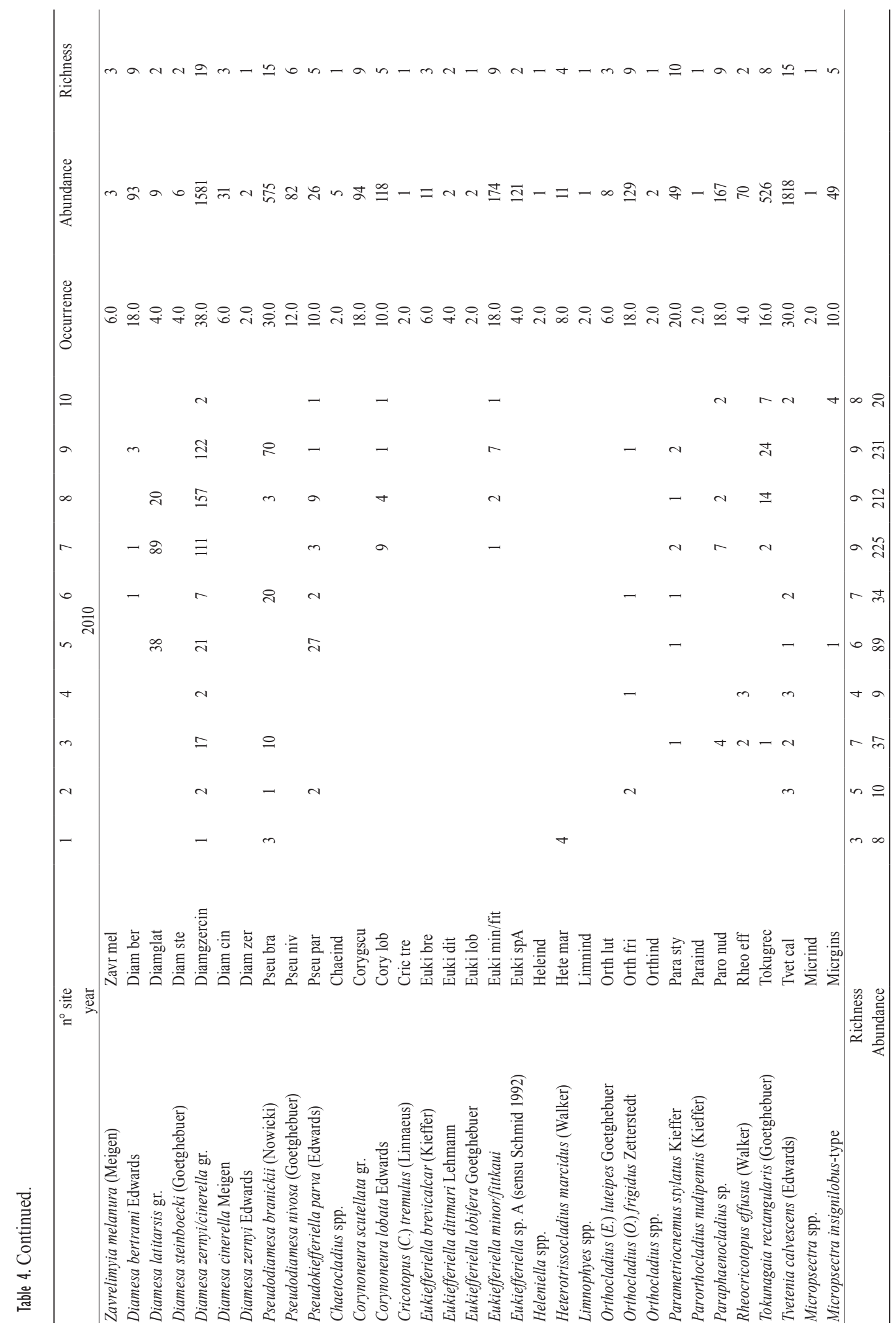


Table 5. Mean (SD) number of taxa and abundance of chironomids collected by kick net in the study stream sites during summer 2002 - $2010(\mathrm{n}=5) ; \mathrm{p}$ = significance of a Mann-Whitney test.

\begin{tabular}{|c|c|c|c|c|c|c|c|}
\hline Site & Number & Type & Basin & Taxon richness & $\mathrm{p}$ & Abundance & $\mathrm{p}$ \\
\hline Grond-OL & 1 & outlet & North & $3.6(1.1)$ & & $14.8(5.3)$ & \\
\hline Mezza-glüna-inlet & 2 & inlet & North & $4.0(1.3)$ & & $46.0(11.0)$ & \\
\hline Mezza-glüna-outlet & 3 & outlet & North & $6.2(0.7)$ & & $89.4(40.1)$ & \\
\hline Immez-north & 4 & inlet & North & $5.2(2.0)$ & & $54.2(28.7)$ & \\
\hline Sura OB & 5 & outlet & South & $8.4(1.4)$ & & $225.0(71.4)$ & \\
\hline Sura-inlet & 6 & inlet & South & $6.8(0.4)$ & & $371.2(294.4)$ & \\
\hline Sura-outlet & 7 & outlet & South & $7.6(0.7)$ & & $247.8(70.1)$ & \\
\hline Immez-south & 8 & inlet & South & $8.2(1.3)$ & & $317.4(106.0)$ & \\
\hline Immez-outlet & 9 & outlet & outlet & $7.0(1.5)$ & & $227.6(55.1)$ & \\
\hline Zeznina & 10 & stream & outlet & $6.8(0.7)$ & & $65.2(23.0)$ & \\
\hline North basin & $1,2,3,4$ & all & & $4.7(0.7)$ & \multirow{2}{*}{0.002} & $51.1(13.1)$ & \multirow{2}{*}{0.001} \\
\hline South basin & $5,6,7,8$ & all & & $7.7(0.5)$ & & $290.3(76.5)$ & \\
\hline \multirow[t]{2}{*}{ North basin } & & period 2002-04 & & $6.5(1.1)$ & \multirow{2}{*}{0.038} & $93.4(26.0)$ & \multirow{2}{*}{0.004} \\
\hline & & period 2005-10 & & $3.6(0.6)$ & & $22.9(5.5)$ & \\
\hline \multirow[t]{2}{*}{ South basin } & & period 2002-04 & & $9.0(1.0)$ & \multirow{2}{*}{$>0.05$} & $512.6(163.5)$ & \multirow{2}{*}{0.009} \\
\hline & & period 2005-10 & & $6.9(0.3)$ & & $142.2(23.0)$ & \\
\hline
\end{tabular}

temperature variable) on the $\mathrm{CoA}$ (Figure 4).

\section{Chironomid diversity in the Macun system}

A total of 49 taxa were collected during this long-term monitoring (2002-10), among which half (25 taxa) were common to ponds and interconnected streams. These results reflected the influence of a lake/pond system on the outlet chironomid fauna. The presence of genera such as Metriocnemus, Paraphaenocladius and Pseudosmittia suggested that the damp soil, the splash-zone of littoral and mosses are also habitats for chironomid larvae.

\section{DISCUSSION}

Chironomids were the most diverse and abundant macroinvertebrate group found in high mountain streams (Lods-Crozet et al. 2001a; Burgherr et al. 2002; Hieber et al. 2005) and lakes/ponds (Boggero \& Lencioni 2006; Füreder et al 2006; von Gunten et al. 2008; Oertli et al. 2008; Catalan et al. 2009). As expected, most of the chironomid taxa in the Macun system are stenothermic, typical of oligotrophic waters and high mountain streams. The assemblage of Macun cirque consisted of mostly oligostenothermic species often occurring in high densities (e.g. Zavrelimyia, Pseudodiamesa, Heterotrissocladius) (Langton 1991, Brooks et al. 2007, Ilyashuk et al. 2009). This phenomenon could be explained by the ability of a few well-adapted species to use time-restricted input of food resources under extreme climatic conditions (CiamporovaZat'ovicova et al. 2010). This biomonitoring is among the first to study chironomid communities in a high alpine lake/pond chain over a long-term period using semi-quantitative sampling. Indeed, 26 ponds/lakes sampled between 1 to 5 occasions and 10 stream sites were monitored during 9 years may explain the overall high regional diversity (49 taxa) for a high mountain pond/lake network. The chironomid diversity could be therefore underestimated since drift pupae and adult collection were not investigated.

The local diversity was relatively low in stream sites (range $3.6-8.4)$ and in pond/lake littorals $(3.5-10.0)$ compared to lowland sites (e.g. Lods-Crozet \& Castella 2009; Koperski 2010; Bouchard \& Ferrington 2011), reflecting the general perception that the harsh conditions determine the species able to persist and complete their life cycle in high elevation waterbodies. The Diamesinae and few Orthocladinae from the Eukiefferiella complex (Eukiefferiella, Tokunagaia, Tvetenia) are known to be the first taxa colonizing glacial-fed streams, being able to tolerate the cold water temperature (Lods-Crozet et al. 2001a, 2001b; Milner et al. 2001). Pseudodiamesa spp. are cold-adapted to harsh physical environments, including freezing and drying (Ilyashuk et al. 2009). The larvae are able to complete their life cycle at water temperatures never exceeding $2{ }^{\circ} \mathrm{C}$ (Lods- 
Crozet et al. 2001b; Milner et al. 2001; Ilyashuk et al. 2009). Furthermore, the presence in ponds M7 and M23 of Diamesa steinboecki, species characteristic of the uppermost glacial waters stretches, confirmed the glacial origin of waters feeding these two ponds in the south basin. Paratanytarsus austriacus is often associated with Bryophyta (more than half of the ponds) and is the dominant taxon in pond M6 which was colonized by a rich and diverse aquatic vegetation. Moreover, Cricotopus and Psectrocladius sordidellus indicated that enough littoral food or organic habitat is available (Langton 1991). Zavrelimyia and Corynoneura larvae, dominant genera in permanent ponds, are typical littoral dweller in high alpine lakes living on periphyton (Brooks et al. 2007). Limnophyes spp. frequently occurred in permanent and temporary ponds (40\%) and their larvae lived in moss in damp soil or stream/littoral zones of lakes (Langton 1991).

The Macun chironomid assemblages are mostly herbivorous and detritivous, feeding mainly on diatoms that are diverse in the catchment and reflecting the heterogeneity of physicochemical conditions (Robinson \& Kawecka 2005).

Despite streams in both basins having stable substrata because of low gradients and flows (Robinson \& Matthaei, 2007) compared to glacial-fed streams, the chironomid fauna were dominated in abundance by the Diamesinae subfamily. The total richness is relatively high (33 taxa) if compared to the one of a glacial-fed stream in the Rhône glacier region at the same range of altitude, where Lods-Crozet et al. (2001a) documented only 10 taxa.

In addition, it can be noted that Tanypodinae, Orthocladiinae and Tanytarsini (88\%) contributed most to the abundance in permanent ponds while Diamesinae and Orthocladiinae (88\%) contributed most in temporary ponds. This was partially noted by Boggero \& Lencioni (2006) that Tanypodinae and Tanytarsini were abundant in the littoral of high elevation lakes in the Alps. A comparison with four lakes located above $2400 \mathrm{~m}$ a.s.l., studied by Boggero \& Lencioni (2006), showed the same range in the number of taxa by lake, the presence of the same dominant taxa (Zavrelimyia, Heterotrissocladius, Corynoneura, Paratanytarsus) and a total richness of 22 taxa. In inlets/outlets, 34 taxa were also identified with the predominance of orthoclads ( 25 taxa). This species composition seems to be a general feature of alpine lakes under extreme conditions and situated above $2000 \mathrm{~m}$ a.sl. (CiamporovaZat'ovicova et al. 2010, Lotter et al. 2000, Boggero \& Lencioni 2006; Füreder et al. 2006).

No obvious temporal trend was detected among the chironomid fauna in ponds frequently monitored (M15, M20, M8t) and the spatial variability between ponds seemed higher than the temporal between years. In contrast, chironomid assemblages in the stream network showed a temporal trend from 2002 to 2009 but it cannot be linked to any clear change at the species level. The higher richness and abundance in stream sites of the south basin could be related to a greater heterogeneity in water physico-chemistry and substrata, and by the presence of moss beds.

As noticed above, the Chironomidae is the most diverse group in this high alpine ponds/lakes and stream network with almost 50 taxa and represent twice of all the other macroinvertebrate groups such as Oligochaeta, Plecoptera, Coleoptera and other Diptera (Robinson \& Oertli 2009, Oertli et al. 2008). Similar results were found in alpine lakes in the Tatras mountains (Slovakia) where chironomids and oligochaetes were the dominant groups (Kownacki et al. 2000, CiamporovaZat'ovicova et al. 2010).

The understanding of environmental factors that influence faunal assemblages is crucial for the protection of these sensitive ecosystems at the catchment level. For example, recent studies highlight the importance of vegetation cover in the catchment for the distribution of macroinvertebrates (Füreder et al. 2006). These aspects are going to become essential in the future, especially in the recognition of a continuous changing world. The reconstruction of past July air temperature from a remote high mountain lake based on chironomid remains by Ilyashuk et al. (2009) shows that the changes in chironomid assemblages were mainly driven by the temperature gradient.

Due to the insular nature of alpine environments, many of the cold stenothermal species will be subject to extinction if water temperatures increase above a certain threshold, perhaps by only a few degrees (e.g. Rosset \& Oertli 2011). Others, such as eurythermic taxa, may act as fugitive species and may expanding their distribution due to temperature changes (Robinson et al. 2006). At the same time, an indirect impact on chironomids through food source changes can also be expected. The epilithic algal biomass could be enhanced by the change in light availability resulting from earlier ice melt and consequently improved environmental conditions for life.

Despite the fact that larval identification is time consuming and requires special taxonomic expertise, our results support the use of chironomids as flagship indicators in the assessment of climatic change in alpine landscapes. The present study contributes to the overall understanding of environmental effects on high mountain waterbodies and ecosystems, and assists in refining research and conservation strategies for the forcasting of expected changes.

\section{ACKNOWLEDGMENTS}

This work was partly supported by the Research Committee from the Swiss National Park. Thanks to Thomas Scheurer and Flurin Filli for logistic support and to everyone who helped in the field: M. Hieber, V. Wenzelides, J. Ruegg, J. Logue, L. Shama, C. Baumgartner, S. Matthaei, S. Blaser, K. Barnard, C. Jolidon, K. Gafner, D. Tonolla, B. Imhof, M. Zbinden, R. Vukelic, S. Mannes,

A. Fijarczyk and T. Buser for streams, and H. Hinden, N. Indermuehle, N. Menetrey, L. Sager, Z. Fleury, M. Massa, A. Stoll, E. Lecomte, A.S. Reymond, C. Ilg and J. O'Rourke for the 
ponds. We are grateful to M. Krafft for the drawing and adaptation of the Macun map. We thank T. Ekrem, B. Ilyashuk, P.H. Langton and O.A. Saether for verification of chironomid species.

\section{REFERENCES}

Boggero A, Lencioni V 2006. Macroinvertebrate assemblages of high altitude lakes, inlets and outlets in the southern Alps. Arch. Hydrobiol. 165: 37-61.

Bouchard RWJr, Ferrington LCJr. 2011. The effects of subsampling and sampling frequency on the use of surface-floating pupal exuviae to measure Chironomidae (Diptera) communities in wadeable temperate streams. Environ Monit Assess 181:205223.

Brooks SJ, Langdon PG, Heiri O. 2007. The identification and use of Palaearctic Chironomidae larvae in palaeoecology. QRA Technical Guide n¹0. Quaternary Research Association. London. 276 p.

Brown LE, Hannah DM, Milner AM. 2003. Alpine stream habitat classification: an alternative approach incorporating the role of dynamic water source contributions. Arct. Antarct. Alp. Res. 35: 313-322.

Burgherr P, Ward JV, Robinson CT. 2002. Seasonal variation in zoobenthos across habitat gradients in an alpine glacial floodplain (Val Roseg, Swiss Alps). J. N. Am. Benthol. Soc. 21: $561-575$.

Catalan J, Barbieri MG, Bartumeus F, Bitusik P, Botev I, Brancelj A, Cogalniceanu D, Manca M, marchetto A, OgnjanovaRumenova N, Pla S, Rieradevall M, Sorvari S, Stefkova E, Stuchlik E, Ventura M. 2009. Ecological thresholds in European alpine lakes. Freshwater Biology 54: 2494-2517.

Chessel D, Dufour AB, Thioulouse J. 2004. The ADE4 package-IOne-table methods. R News 4:5-10.

Ciamporová-Zat'ovicová Z, Hamerlik L, Sporka F, Bitusik P. 2010. Littoral benthic macroinvertebrates of alpine lakes (Tatra Mts) along an altitudinal gradient: a basis for climate change assessment. Hydrobiologia 648 : 19-34.

Dolédec S, Chessel D. 1987. Rythmes saisonniers et composantes stationnelles en milieu aquatique I- Description d'un plan d'observations complet par projection de variables. Acta Ecologica, Ecologia Generalis 8: 403-426.

Dolédec S, Chessel D. 1989. Rythmes saisonniers et composantes stationnelles en milieu aquatique II- Prise en compte et élimination d'effets dans un tableau faunistique. Acta Ecologica, Ecologia Generalis 10: 207-232.

Füreder L, Ettinger R, Boggero A, Thaler B, Thies H. 2006. Macroinvertebrate diversity in alpine lakes : effects of altitude and catchment properties. Hydrobiologia 562 : 123-144.

Heck KL, van Belle GJr, Simberloff D. 1975. Explicit calculation of the rarefaction diversity measurement and the determination of sufficient sample size. Ecology 56: 1459-1461.

Hieber M, Robinson CT, Uehlinger U, Ward JV. 2005. A comparison of benthic macroinvertebrate assemblages among different types of alpine streams. Freshwater Biology 50: 2087-2100.

Hinden H, Oertli B, Menetrey N, Sager L, Lachavanne JB. 2005. Alpine pond biodiversity: what are the related environmental variables? Aquatic Conservation: Marineand Freshwater Ecosystems 15: 613-624.
Hurlbert SH. 1971. The nonconcept of species diversity: a critique and alternative parameters. Ecological Monographs 54: 187211.

Ilg C, Castella E. 2006. Patterns of macroinvertebrate traits along three glacial stream continuums. Freshwater Biology 51: 840853.

Ilyashuk B, Gobet E, Heiri O, Lotter AF, van Leeuwen J, van der Knaap WO, Ilyashuk E, Oberli F, Ammann B. 2009. Lateglacial environmental and climatic changes at the MalojaPass, Central Swiss Alps, as recorded by chironomids and pollen. Quaternary Science Reviews 28: 1340-1353.

Ilyashuk B, Ilyashuk E, Makarchenko EA, Heiri O. 2010. Midges of the genus Pseudodiamesa Goetghebuer (Diptera, Chironomidae): current knowledge and palaeoecological perspective. Journal of Paleolimnology 44: 667-676.

Knispel S, Castella E. 2005. Disruption of a longitudinal pattern in environmental factors and benthic fauna by a glacial tributary. Freshwater Biology 48: 604-618

Koperski P. 2010. Diversity of macrobenthos in lowland streams: ecological determinants and taxonomic specificity. Journal of Limnolology 69: 88-101.

Kownacki A, Galas J, Dumnicka E, Mielewczyk S. 2000. Invertebrate communities in permanent and temporary high mountain lakes (Tatra Mts). International Journal of Limnology 36: 181-188.

Krebs CJ. 1999. Ecological methodology. Addison Wesley Longman, Inc. $620 \mathrm{p}$.

Langton PH. 1991. A key to pupal exuviae of West Palaearctic Chironomidae. Privately published by P.H. Langton, 5 Kylebeg Av., Mountsandel, Cleraine, Co. Londonderry, Northern Ireland.

Lencioni V, Rossaro B. 2005. Microdistribution of chironomids (Diptera: Chironomidae) in Alpine streams: an autoecological perspective. Hydrobiologia 533: 61-76.

Lencioni V, Marziali L, Rossaro B. 2007. I Ditteri Chironomidi: morfologia, tassonomia, ecologia, fisiologia e zoogeografia. Quaderni del Museo Tridentino di Scienze Naturali 1, 172 pp.

Lods-Crozet B, Castella E, Cambin D, Ilg C, Knispel S, MayorSimeant H. 2001a. Macroinvertebrate community structure in relation to environmental variables in a Swiss glacial stream. Freshwater Biology 46: 1641-1661.

Lods-Crozet B, Lencioni V, Olafsson JS, Snook D, Velle G, Brittain JE, Castella E, Rossaro, B. 2001b. Chironomid (Diptera: Chironomidae) communities in six European glacier-fed streams. Freshwater Biology 46: 1791-1809.

Lods-Crozet B, Castella E. 2009. Colonisation by midges (Chironomidae, Diptera) of recently-created shallow ponds: implications for the restoration of lacustrine fringing wetlands. International Journal of Limnology 45 : 257-266.

Lotter AF, Hofmann W, Kamenik C, Lami A, Ohlendorf C, Sturm M, van der Knaap WO, vau Leeuwen J. 2000. Sedimentological and biostratigraphical analyses of short sediment cores from Hagelseewli (2339 m a.s.l.) in the Swiss Alps. Journal of Limnology 59(Suppl. 1): 53-64.

Maiolini B, Lencioni V, Boggero A, Thaler B, Lotter AF, Rossaro B. 2006. Zoobenthic communities of inlets and outlets of high altitude Alpine lakes. Hydrobiologia 562: 217-229.

Milner AM, Brittain JE, Castella E, Petts GE. 2001. Trends of macroinvertebrate community structure in glacial-fed rivers in 
relation to environmental conditions: a synthesis. Freshwater Biology 46: 1833-1848.

Oertli B, Auderset Joye D, Castella E, Juge R, Lehmann A, Lachavanne JB. 2005. PLOCH: a standardized method for samplig ans assessing the biodiversity in ponds. Aquatic Conservation: Marine and Freshwater Ecosystems 15: 665-679.

Oertli B, Indermuehle N, Angélibert S, Hinden H, Stoll A. 2008. Macroinvertebrate assemblages in 25 high alpine ponds of the Swiss National Park (Cirque of Macun) and relation with environmental variables. Hydrobiologia 597: 29-41.

Robinson CT, Burgherr P, Malard F, Tockner K, Uelinger U. 2003. Synthesis and perspectives. In: Ward JV and Uelinger U (eds). Ecology of a glacial flood plain. Kluwer. Pp 257-269.

Robinson CT, Kawecka B. 2005. Benthic diatoms of an Alpine stream/lake network in Switzerland. Aquatic Sciences 67: 492506.

Robinson CT, Matthaei S. 2007. Hydrological heterogeneity of an alpine stream/lake network in Switzerland. Hydrological Processes 21: 3146-3154.

Robinson CT, Hieber M, Wenzelides, Lods-Crozet B. 2007. Macroinvertebrate assemblages of a high elevation stream/lake network with an emphasis on the Chironomidae. Fundamental and Applied Limnology 169(1): 25-36.

Robinson CT, Oertli B. 2009. Long-term biomonitoring of alpine waters in the Swiss National Park. Eco. Mont 1(1): 2334.

Rosset V \& Oertli, B. 2011. Freshwater biodiversity under climate warming pressure: identifying the winners and losers in temperate standing waterbodies. Biological Conservation 144: 2311-2319.

Rüegg, J, Robinson CT. 2004 Comparison of macroinvertebrate assemblages of permanent and temporary streams in an Alpine flood plain, Switzerland. Fundamental and Applied Limnology 161: 489-510.

R Development Core Team 2009. R: A language and environment for statistical computing. R Foundation for Statistical Computing, Vienna, Austria. ISBN 3-900051-07-0, URL http://www.Rproject.org.

Saether OA. 1995. Metriocnemus van der Wulp: Seven new species, revision of species, and new records (Diptera : Chironomidae). Annales de Lomnologie 31: 35-64.

Schmid PE 1993. A key to the larval Chironomidae and their instars from Austrian Danube region streams and rivers. Part 1: Diamesinae, Prodiamesinae and Orthocladiinae. Wasser und Abwasser Suppl. 3/93: 1-513.

Tockner K, Malard F, Burgherr P, Robinson CT, Uelinger U, Zah R, Ward JV. 1997. Physico-chemical characterization of channel types in a glacial floodplain ecosystem (Val Roseg, Switzerland). Archiv für Hydrobiologie 140: 433-463.

Von Gunten L, Heiri O, Bigler C, vau Leeuwen J, Casty C, Lotter AF, Sturm M. 2008. Seasonal temperatures for the past $\sim 400$ years reconstructed from diatom and chironomid assemblages in ahigh-altitude lake (Lej da la Tscheppa, Switzerland). Journal of Paleolimnology 39: 283-299.

Wiederholm T. 1983. Chironomidae of the Holarctic region. Keys and Diagnoses. Part 1. Larvae. Entomologica Scandinavica Suppl. 19: 1-449.

Wiederholm T. 1986. Chironomidae of the Holarctic region. Keys and Diagnoses. Part 2. Pupae. Entomologica Scandinavica Suppl. 28: $1-482$. 